\title{
HELMRATH, Johannes, MÜLLER, Heribert, WOLFF, Helmut, Studien zum 15. Jahrhundert. Festschrift für Erich Meuthen
}

Joseph Morsel

\section{OpenEdition}

\section{Journals}

Édition électronique

URL : http://journals.openedition.org/ifha/1442

DOI : 10.4000/ifha. 1442

ISSN : 2198-8943

Éditeur

IFRA - Institut franco-allemand (sciences historiques et sociales)

Référence électronique

Joseph Morsel, «HELMRATH, Johannes, MÜLLER, Heribert, WOLFF, Helmut, Studien zum 15.

Jahrhundert. Festschrift für Erich Meuthen », Revue de l'IFHA [En ligne], Date de recension, mis en ligne le

01 janvier 1998, consulté le 22 septembre 2020. URL : http://journals.openedition.org/ifha/1442 ;

DOI : https://doi.org/10.4000/ifha.1442

Ce document a été généré automatiquement le 22 septembre 2020.

(CIFHA 


\title{
HELMRATH, Johannes, MÜLLER, Heribert, WOLFF, Helmut, Studien zum 15. Jahrhundert. Festschrift für Erich Meuthen
}

\author{
Joseph Morsel
}

Le thème de la »crise« de la fin du Moyen Age hante l'historiographie médiévale, notamment celle du XIVe s. avec ses famines, épidémies, pogroms et perspectives apocalyptiques. František Graus y a consacré plusieurs ouvrages de référence, depuis son bilan historiographique de 1969 (Das Spätmittelalter als Krisenzeit. Ein Literaturbericht als Zwischenbilanz = Mediævalia Bohemica, Suppl. 1) jusqu'aux deux éditions de son Pest - Geißler - Judenmorde. Das 14. Jahrhundert als Krisenzeit (Göttingen, 1987 et 1988). L'ouvrage dirigé par W.B. prétend, par son titre et sa quatrième de couverture, se pencher sur le problème que pose la conception catastrophiste, négative (»déclin«, "automne«) du XIVe s., et ce de manière interdisciplinaire. Ce qui imposerait soit de s'interroger sur la notion de "crise« ellemême (et de lui restituer sa dimension constructive), soit de mettre un point d'interrogation après Krisenzeit si l'on conserve le sens courant, négatif, du mot. Rien de tout cela n'est fait. Le choix du XIVe s. est justifié par l'argument implicite de "l'époque-charnière«: beaucoup de choses s'y sont produites qui marquent la postérité... On croirait lire un étudiant cherchant à justifier a posteriori le choix de tel ou tel sujet. Seule une contribution se penche sur »la crise de la pensée philosophique au début du XIVe siècle« (R. IMBACH); et si l'on conçoit le terme "crise« en son sens propre de "tournant «, »charnière«, on peut y ajouter l'étude du Décaméron de Boccace en tant qu'œuvre-charnière (P. GEYER); du côté des catastrophes, on trouvera également une présentation de la peste de 1347-1351, assortie de réflexions sur la médecine médiévale en général (G. KEIL), voire également un rappel de l'installation des papes à Avignon à l'origine du Grand Schisme. Quant à l'interdisciplinarité, elle est visiblement confondue avec la pluri-disciplinarité: l'ouvrage apparaît comme une juxtaposition d'études plus ou moins fouillées sur des sujets divers dont le seul point 
commun est le XIVe s. La plupart des contributions traitent en effet soit d'une œuvre (outre le Décaméron déjà cité, le Purgatorio de Dante, le Livre des choses naturelles de Konrad von Megenberg, le Canzoniere de Pétrarque, les Contes de Cantorbéry de Chaucer, l'Ackermann aus Böhmen), soit d'une personnalité (Maître Eckhart), soit encore d'un domaine culturel (outre la philosophie sus-mentionnée, l'art ainsi que la musique). Bref, une cotte mal taillée, à mi-chemin entre le manuel de base et le recueil de travaux pointus. Sans doute inutile.

2 Si des »études sur le XVe s.« sont offertes à E. Meuthen pour son 65e anniversaire, c'est qu'il s'est consacré des années durant à ce 'siècle charnière' (en français dans le texte de préface!), auquel il a même consacré un manuel (paru chez le même éditeur que les présents mélanges). Gageons que, pas plus que le XIVe s. de W. Buckl, le XVe s. d'E. Meuthen n'est un siècle-charnière, mais cela n'enlève rien à l'intérêt du volume. 51 contributions, $1100 \mathrm{p}$. de texte: impossible de résumer le volume, heureusement structuré en six champs - qu'E. Meuthen a lui-même parcouru antérieurement. Une première section est consacrée aux conciles de Constance et Bâle, envisagés sous l'angle soit des participants à ceux-ci (Siennois, Anglais, Franco-Bourguignons, etc.), soit des discussions théologiques qui y ont été menées (sur le conciliarisme, l'infaillibilité pontificale, l'immaculée conception, l'hérésie). Une deuxième section porte sur Nicolas de Cues (puisque E. Meuthen a été le moteur de la Cusana, l'entreprise de recherches et publications sur N. de Cues): y sont envisagés certains aspects de la culture et de l'activité ecclésiastique du Cusanus. La troisième section rassemble sous la rubrique "Piété, éducation et culture« des contributions analysant des documents particuliers (un exemplum, deux textes de dévotion, un catalogue de bibliothèque, une carte de Pierre d'Ailly, un traité sur l'usure), ou alors portant sur telle ou telle université (Iéna, Cracovie, Pavie). Une quatrième section traite de la Renaissance et de l'Humanisme, consacrée à des auteurs et œuvres pris individuellement (Lorenzo Valla, Marsile Ficin, Jean Tinctoris, Hartmann Schedel), ou alors à des grands facteurs (Renaissance italienne, manuscrits grecs, interrogations religieuses). La cinquième section réunit des textes portant sur l'Empire et l'Europe, étiquette large et non descriptive qui permet de mettre ensemble des textes traitant d'épisodes politiques internes à l'Empire (diplomatie, guerre, fiscalité), de faits romains, de comportements espagnols certainement paradigmatiques. La dernière section est urbaine (un texte sur la perception des villes v. 1500) et plus particulièrement colonaise (piété, clergé, églises, paroisses, communauté). Les »Mélanges Meuthen«, par le nombre, le bon niveau d'information individuel et la variété des contributions (malgré leur polarisation autour de quelques points forts), sont probablement destinés à devenir une référence. 